\title{
MACROHABITAT SELECTION BY THE ORB WEAVING SPIDER, MICRATHENA GRACILIS.
}

\author{
By Margaret A. Hodge* \\ Department of Entomology, University of Georgia, \\ Athens, Georgia 30602
}

\section{INTRODUCTION}

Animals often do not occupy all potential habitats even when they are capable of dispersing into unoccupied areas. This may reflect a "choice" by individuals not to live in certain habitats. In theory, habitat selection behaviors may evolve when large differences between habitats result in differential survival and reproduction rates. If an animal cannot survive and reproduce everywhere, natural selection will favor recognition of suitable habitats (Levins 1968; Krebs 1985).

The mobility and activity patterns of many animals make them difficult subjects for studies of habitat selection. Web building spiders, however, are an exception. Web conspicuousness and the relative ease of marking and following individuals makes them ideal subjects for studying the behavioral mechanisms involved in habitat choice. Micrathena gracilis (Walckenaer) (Araneae: Araneidae), an orb weaving spider, characteristically builds webs which span wide spaces in shady deciduous forests, and rarely occur in adjacent successional areas (Elliot 1930; Uetz et al., 1978; Biere \& Uetz 1981; Hartsock 1983; Hodge 1985). In this study, release experiments were conducted to determine whether $\boldsymbol{M}$. gracilis actively selects deciduous forests, and if so, what environmental variables influence this choice.

\section{Methods AND Materials}

Study organism

Members of the Neotropical genus Micrathena are mostly diurnal, forest dwelling, orb weaving spiders. Although most species are

*Present address: Department of Biological Sciences, University of Cincinnati, Cincinnati, Ohio 45221

Manuscript received by the editor July 24, 1987. Publication delayed on request of author. 
tropical, M. gracilis ranges into temperate North American deciduous forests east of the Rocky Mountains (Levi 1985). This spider builds an orb web within a rectangular or triangular silk frame which is typically located 1-3 m high and spans large open spaces in the forest understory. The orb portion of the web is removed in the evening and rebuilt at dawn. The frame, however, may persist at the same site for many days. In the southeastern United States $M$. gracilis reaches maturity by mid-to-late July. There is extreme sexual dimorphism, and upon reaching maturity males cease building webs. Therefore, adult females were used in this study, since they maintain webs throughout the summer, and these webs are crucial to survival and egg production.

\section{Release experiments}

This study was conducted during July and August 1983 in a forested area which included a transition zone from an open pine stand to a deciduous forest. The privately-owned site was located in Griffen, Georgia (4.5 miles W. of the Spalding Co./Butts Co. line). Canopy tree species in the deciduous section were Quercus velutina Lam., $Q$. nigra L., Acer rubrum L., and Pinus taeda L. The pine stand consisted of mature $P$. taeda, young $P$. taeda $(<2 \mathrm{~m}$ tall), $Q$. nigra and Rubus sp. (both $<1 \mathrm{~m}$ tall). The pine stand was bordered on one side by the deciduous area; the opposite side was bordered by a row of small pine trees, beyond which was a grape arbor; a dry ditch and a paved road ran along one side, and opposite this was continuation of pine forest. The deciduous forest area was also bordered by the road, and the two other sides were a continuation of deciduous habitat.

Release experiments were conducted in a $32 \times 32 \mathrm{~m}$ plot encompassing both pine and deciduous forest. Each square meter of the study plot was assigned a number corresponding to numbered flags which bordered the area at $1 \mathrm{~m}$ intervals. Prior to initiation of spider manipulations, the height of all vegetation in each square meter of the study plot was measured, and the presence or absence of pine canopy and deciduous canopy was recorded.

All of the adult female $M$. gracilis present were collected from the study plot and the surrounding area $(n=24)$. Spiders were marked by affixing newsprint letters to the dorsal surface of the abdomen with clear nail polish, providing each with a unique letter identity, 
and retained for 12 hours in one-dram plastic vials at room temperature to ascertain that there were no detrimental effects due to the marking procedure. At 0700 hours on 21 July, the 24 marked spiders were released into randomly chosen quadrats (using numbers selected sequentially from a random number table), resulting in 15 spiders being released into the pine stand, and 9 into the deciduous forest. I censused spider locations and distance moved (if any) each morning between 0800 and 0900 hours, from 22 July through 2 August. Web sites were marked with flags placed in the ground below the web, and the letter identity of the spider was written on the flag with waterproof ink.

In order to clarify whether the movement patterns of spiders in the two habitats were different, I repeated the experiments using a different release protocol. I recollected the 14 spiders remaining in the study area on 18 August and released them into randomly chosen quadrats within the pine stand on 19 August. Seventeen additional spiders, collected from adjacent woods, were marked and released at random points within the deciduous area on 24 August. All spiders were censused from the time of release through 9 September (see Table 1).

Table 1. Canopy cover at spider release points and endpoints within each habitat.

\begin{tabular}{lllr}
\hline & $\begin{array}{l}\text { Canopy type } \\
\text { release point }\end{array}$ & $\begin{array}{l}\text { Canopy type } \\
\text { end point }\end{array}$ & $\begin{array}{r}\% \text { total released } \\
(\mathrm{N}=19)\end{array}$ \\
\hline Deciduous stand & Open & Open & $5 \%$ \\
& Open & Deciduous & $16 \%$ \\
& Mixed & Deciduous & $5 \%$ \\
& Deciduous & Open & $21 \%$ \\
PINE STAND & Deciduous & Deciduous & $53 \%$ \\
& Open & Open & $53 \%$ \\
& Open & Deciduous & $17 \%$ \\
& Pine & Open & $5 \%$ \\
& Pine & Deciduous & $10 \%$ \\
& Mixed & Deciduous & $5 \%$ \\
& Deciduous & Deciduous & $10 \%$ \\
\hline
\end{tabular}

${ }^{*} 15 \%$ of these spiders did not build webs 


\section{Environmental measurements}

Over a five-day-period during the final release experiments, some of the environmental factors which may have caused spiders to relocate were monitored in the two habitats. In both the deciduous forest area and the pine stand, temperature and humidity were recorded every three hours from 0900 through 1800 hours, at two randomly chosen quadrats. Humidity was measured using a Mason's hygrometer (Taylor Instruments, Arden, N.C.) and temperature readings were obtained from the dry bulb of this instrument. Sticky traps were set out at these same sites to estimate prey availability in the two habitats. These traps consisted of a $20 \mathrm{~cm}$ diameter embroidery hoop covered with a double layer of cheese cloth. The cheese cloth was coated with Stickem Special (Seabright Enterprises, Emeryville, Calif.), an insect trapping compound. The traps were suspended one meter above the ground (which approximates the average height of a $M$. gracilis web; (Hodge 1985)). I set these out at 0700 and retrieved them at 1800 hours. Trapped insects were removed and identified to order and their body lengths were measured to the nearest $\mathrm{mm}$. During this five-day-period, all webs in the study area were visited every three hours and thermoregulatory positioning by the spider and web condition (damaged or undamaged) were recorded.

\section{RESULTS}

I was able to follow 19 of the 23 spiders released into the pine stand, and 19 of the 32 released into the deciduous forest. Residence times at web sites for spiders released into each habitat were significantly different ( $t$-test, $p<0.01 ;$ Fig. 1$)$. The mean residence time at a given site by spiders in the deciduous forest was 8 days (S.D. $=4)$, whereas spiders in the pine stand only stayed an average of 1 day (S.D. = 2) at a web site. By September 9, the last census day, almost all spiders released into the pine stand had, through successive web relocations, moved into the deciduous forest or had disappeared from the area (Fig. 2). Exceptions included three spiders that did not build webs over the six days that they were observed before they disappeared. Three other spiders successfully maintained webs in the pine stand, but all were near the transition zone to the deciduous section (Fig. 2). None of the spiders released into the deciduous forest was ever observed to have moved into the pine stand (Fig. 3). Spiders released within the deciduous woods usually moved from a site of deciduous canopy to similar sites, but sometimes moved to quadrats with no canopy (Table 1). 


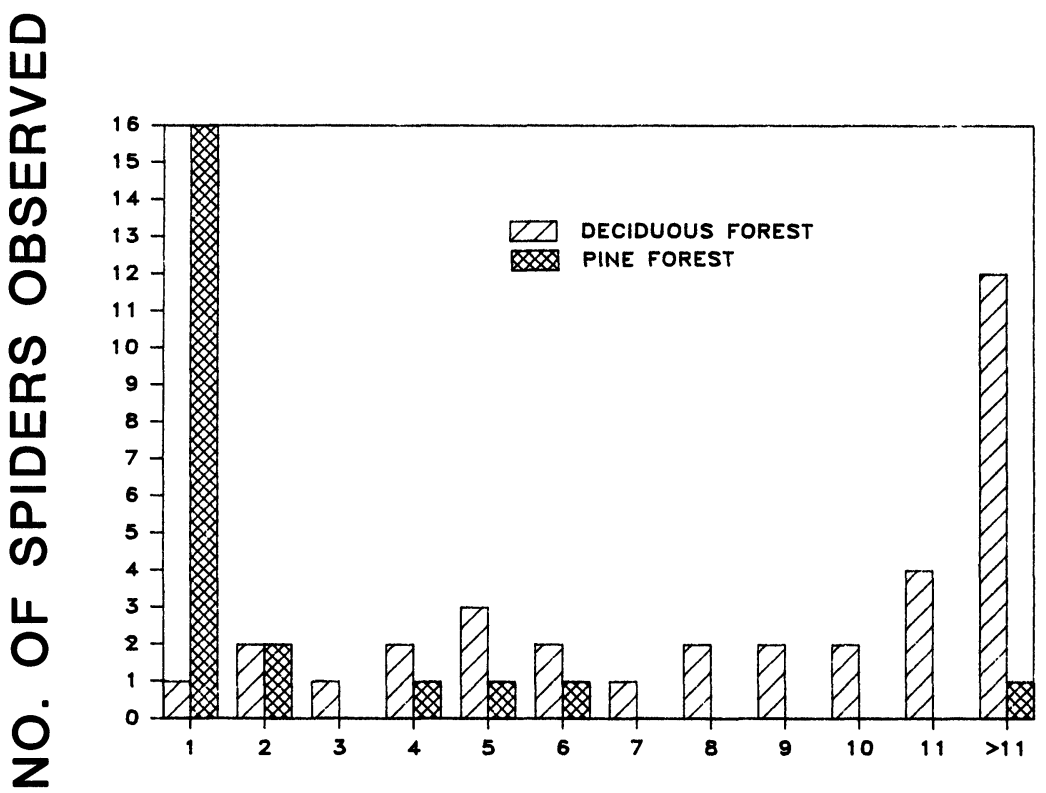

\section{DAYS AT WEB SITE}

Figure 1. Comparison of web site residence times of spiders released into the pine forest and the deciduous forest (significantly different, $\mathrm{p}<0.01$ ).

If spider web site relocations occur at random, then the expected distribution of time intervals between relocations should follow a negative exponential distribution, which describes random events over a time-course (Bailey 1964; Ross 1970). Spider residence times in each habitat were compared to values expected from a fitted negative exponential distribution. There was no significant difference between the observed residence times and those expected for the pine stand $(0.01<0.05 ;$ Fig. 4$)$, supporting a random movement hypothesis. In contrast, observed and expected residence times in the deciduous woods were highly significantly different $(p<0.001$; Fig. 5).

A much higher percentage of quadrats had no canopy in the pine stand than in the deciduous woods; the deciduous area had a higher percentage of canopy than did the pine stand (Table 2). The quantity of vegetation below $1 \mathrm{~m}$ in each quadrat of the pine versus the deciduous area was not significantly different (t-test, $p>0.05$ ). 


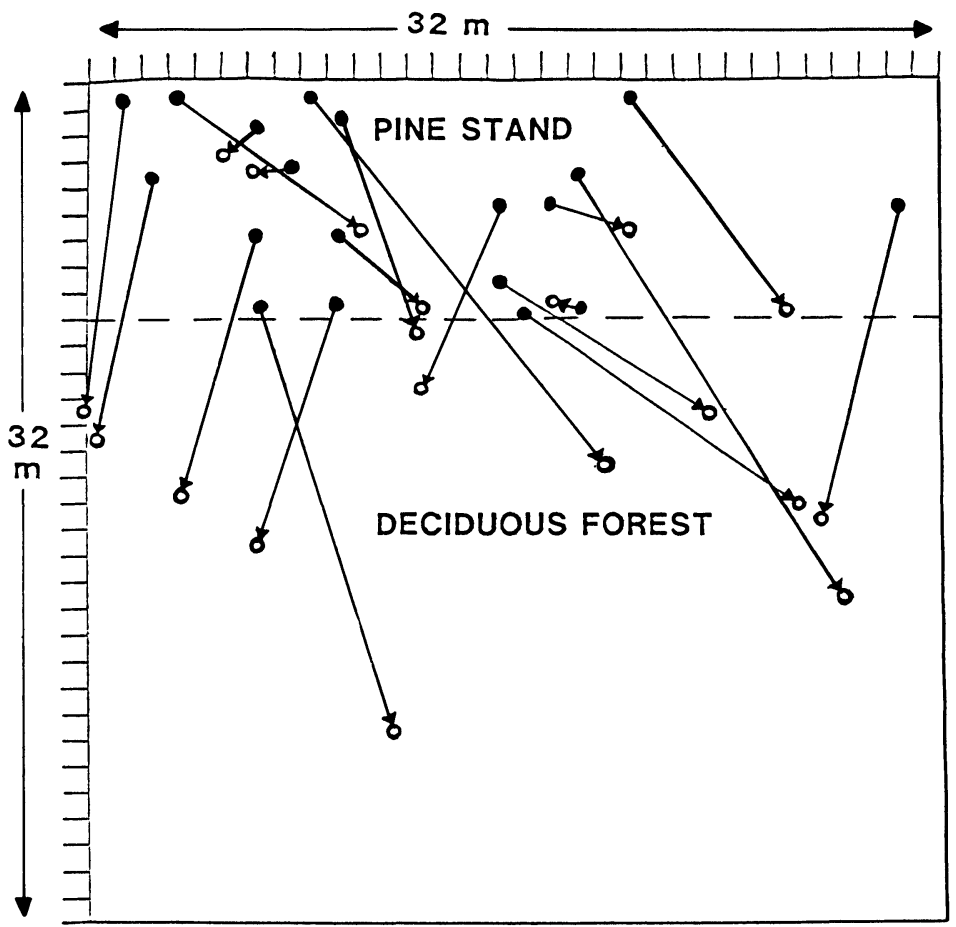

Mean web site residence time $=1$ day \pm 3 days

Mean distance moved $=9.93 \mathrm{~m}$

Figure 2. Release points and end points of spiders released into the open pine stand (solid circles indicate release point, open circles indicate where the spider was seen last).

However, a significant difference did exist in the amount of vegetation between 1-3 m high and over $3 \mathrm{~m}$, with the deciduous area having more of this taller vegetation than the pine stand ( $t$-test, $p<$ 0.01 ). Of the other environmental parameters measured, only insect length showed a significant difference between habitats (Table 3). A Mann-Whitney $U$ test indicates that no significant difference existed in humidity or ambient temperature levels between the deciduous forest and the pine stand $(\mathrm{p}>0.01)$. Likewise, a Mann-Whitney $U$ test on the number of insects caught each day at each sticky trap indicates no difference between habitats $(p>0.01)$. 


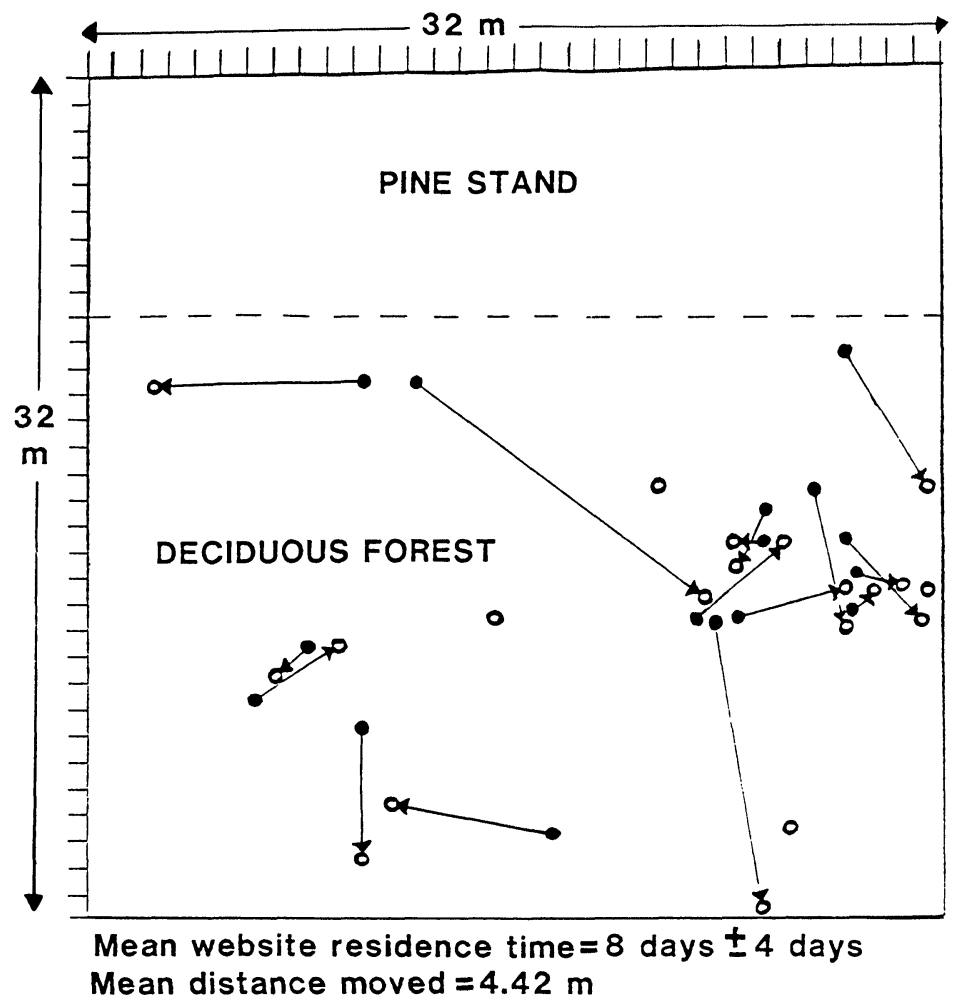

Figure 3. Release points and end points of spiders released into the deciduous forest (solid circles indicate release point, open circles indicate where the spider was seen last).

Several observations of spider behavior and web condition suggest additional environmental differences between pine and deciduous forests that may affect web site tenacity. Spiders under heat stress hang on the web in such a way as to minimize the amount of body surface area exposed to the direct rays of the sun (Krakauer 1972; Carrel 1978; Robinson \& Robinson 1974, 1979; Biere 1977; Biere \& Uetz 1981). Five days of observations made at 3 hour intervals revealed that by 1200 hours, all spiders in the pine stand were assuming this thermoregulatory position. None of the spiders in the deciduous forest were ever observed to posture in this manner. This 


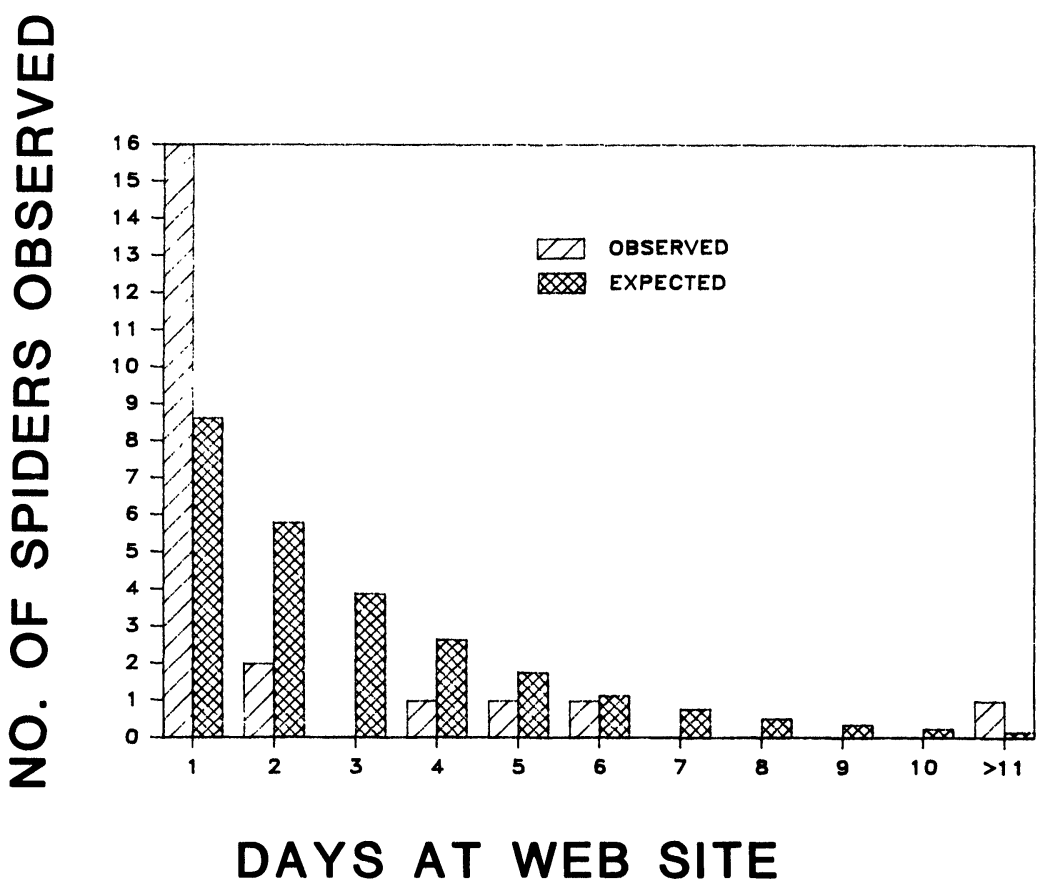

Figure 4. Comparison of distribution of residence times of spiders released into the pine stand with that expected from a random movement hypothesis (no significant difference, $0.01<\mathrm{p}<0.05$ ).

may be directly related to the differences in canopy cover between the two habitats (Table 2). Over this same five-day-period, only $4 \%$ of the observations of webs in the deciduous forest noted web destruction $(n=66)$, in contrast to $22 \%$ noted in the pine stand $(n=$ 59). Such collapsed webs may have been caused by occasional strong breezes, large insects flying through, or predation attempts by birds or wasps.

\section{Discussion}

Field experiments demonstrating active habitat selection are relatively uncommon. Wecker (1963) and Douglas (1976) used release experiments which revealed habitat preference in rodents. Among insects, the occurrence of discriminating habitat selection has been shown for digger wasps (Brockmann 1979), honeybees (Lindauer 


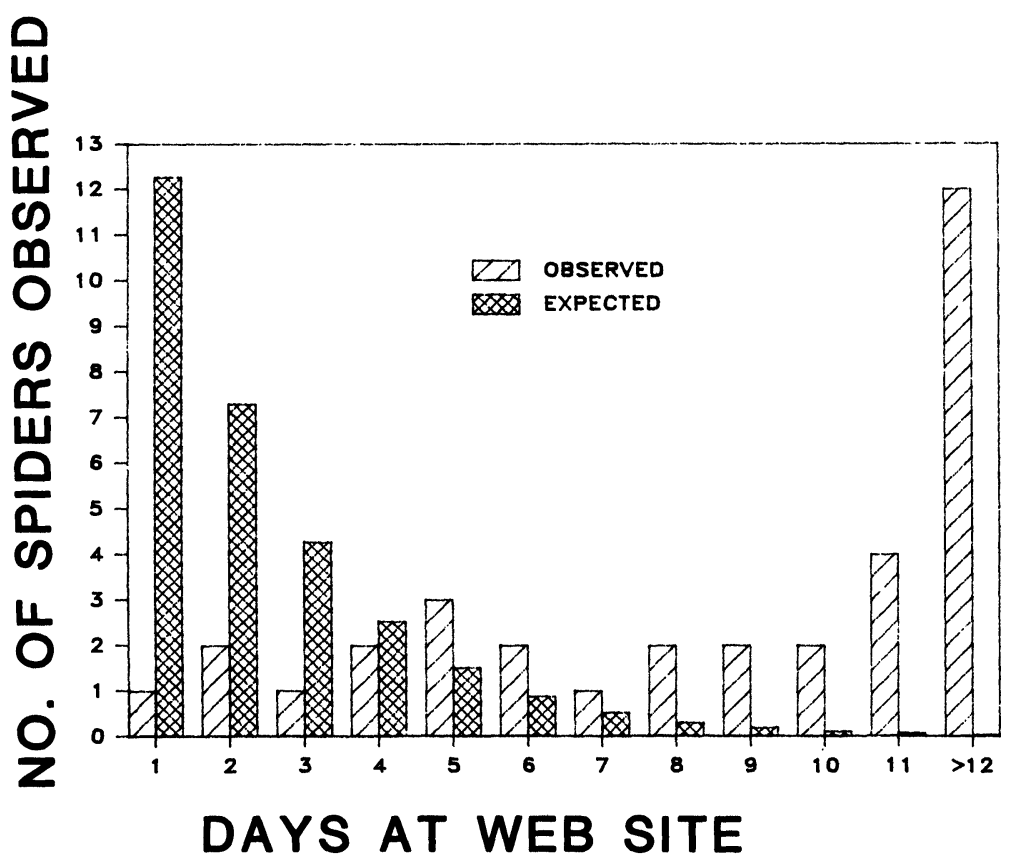

Figure 5. Comparison of distribution of residence times of spiders released into the deciduous forest with that expected from a random movement hypothesis (significantly different, $\mathrm{p}<0.001$ ).

1961) and aphids (Whitham 1979). Enders (1972) found that fielddwelling orb weavers (Argiope spp.) released into wooded habitats did not remain in the wooded area, but successively relocated their webs until they came to a field situation. This is similar to the behavior observed in this experiment. The observation that spiders released into the pine stand moved into the deciduous forest, whereas spiders released into the deciduous forest remained there, suggests that $M$. gracilis prefers that particular type of habitat. Further evidence of habitat preference is suggested by the significantly shorter residence times at pine stand web sites compared to those in the deciduous forest area.

Although five days is a relatively short period of time, weather conditions at the time of environmental data collection were representative of those present throughout the entire study, during which weather conditions were very constant. The results presented here 
Table 2. Distribution of canopy types in each of the two habitats (\% area covered).

\begin{tabular}{lcc}
\hline Canopy type & Pine Stand & Deciduous Stand \\
\hline Open & $64 \%$ & $33 \%$ \\
Pine & $30 \%$ & $5 \%$ \\
Mixed & $2 \%$ & $5 \%$ \\
Deciduous & $4 \%$ & $57 \%$ \\
\hline
\end{tabular}

indicate no difference in humidity or ambient temperature between the deciduous forest area and the pine stand. It would therefore seem that if habitat selection was based on ambient temperature or humidity, spiders would have been equally likely to move from the deciduous forest to the pine stand.

Prey availability, if different between the two macrohabitats, might provide a basis for macrohabitat selection. The sticky trap data indicate a significant difference in insect lengths between the habitats, suggesting that more biomass may be available in the deciduous forest. In addition, the higher frequency of web destruction in the pine stand may have reduced the time available on the web (which reduces the time available for intercepting prey). However, these data may not accurately reflect the prey which the spiders actually sampled, as the precision with which sticky traps represent prey intercepted by webs and captured by spiders is questionable (Castillo \& Eberhard 1983).

Habitat preferences based on structural characteristics are a factor limiting the distribution of some spider species (Eberhard 1971; Colebourn 1974; Enders 1976). Hartsock (1983) suggests that such preferences may explain the different distributions of $M$. gracilis and Verrucosa arenata (Walckenaer) within the forest. The importance of structural properties in construction and maintenance of webs may be similarly involved in this study. The length and position of the bridge thread, which is the basic foundation of the web, is controlled by the spatial distribution of attachment sites (vegetation). Suitable attachment sites are vegetation between 1-3 m tall, or taller. This type of vegetation was significantly less abundant in the pine stand. The deciduous forest provided more attachment sites plus amelioration of destructive air currents (as seen by the lower percentage of web destruction in the deciduous area).

Several studies have demonstrated that solar radiation can have profound effects on the behavior of orb weaving spiders (Krakauer 
Table 3. Mean and standard-deviation (S.D.) of environmental parameters measured in each habitat.

\begin{tabular}{lcc}
\hline Parameter & Pine Stand & Deciduous Stand \\
\hline Relative humidity & & \\
$\quad$ Mean & $53 \%$ & $54 \%$ \\
S.D. & $20 \%$ & $30 \%$ \\
Temperature & & \\
Mean & $33^{\circ} \mathrm{C}$ & $32^{\circ} \mathrm{C}$ \\
S.D. & $5^{\circ} \mathrm{C}$ & $3^{\circ} \mathrm{C}$ \\
Prey/Sticky Trap/Day & & \\
Mean & 7.2 & 4.6 \\
S.D. & 2.4 & 2.7 \\
Prey size (mm) & & \\
Mean & $2.4^{* *}$ & $4.6^{* *}$ \\
S.D. & 1.4 & 2.9 \\
Attachment points $<1 \mathrm{~m}$ & & \\
Mean & 1.78 & 0.70 \\
S.D. & 0.92 & 1.05 \\
Attachment points 1-3 m & & \\
Mean & $0.29 * *$ & $0.45^{* *}$ \\
S.D. & 0.54 & 0.62 \\
Attachment points $>3 \mathrm{~m}$ & & \\
Mean & $0.05^{*}$ & $0.39 *$ \\
S.D. & 0.23 & \\
& & \\
\hline
\end{tabular}

*significantly different; $\mathrm{t}$-test, $\mathrm{p}<0.01$

**significantly different; $t$-test, $\mathrm{p}<0.001$

1972; Robinson \& Robinson 1974; Tolbert 1976; Carrel 1978). Differences in the canopy of pine and deciduous forests may affect the intensity of solar radiation reaching spiders in webs below. The deciduous woods had a much higher percentage of deciduous canopy, which is more effective than pine canopy in providing shade. Biere and Uetz (1981) have shown that even within the forest, $M$. gracilis adjusts the orientation of the web to minimize intense solar radiation in open patches. They also found that spider body temperature was positively correlated with the amount of solar radiation striking the animal. It is therefore possible that heat stress (as indicated by thermoregulatory posturing) in the pine stand contributed to web relocation. Experiments with Micrathena schreibersi (Perty) by Robinson and Robinson (1974) showed that 
sunlight which was redirected with a mirror down the plane of the web onto the ventral surface of the spider (similar to the sun's rays at noon) caused the spider to assume a posture which minimized the body surface exposed to the light/heat source. In similar experiments, Biere (1977) redirected the sun's rays so that the light was directly striking individual $M$. gracilis. He maintained this light/ heat source until the spiders retreated from the hub to the upper bridge-thread attachment point. Seven of 12 individuals thus treated abandoned their former web sites the following day. The relocation response observed in this study may be similar to that observed by Biere (1977). Exposure to insolation is sporadic in deciduous forests, and can usually be dealt with using web orientation and/or thermoregulatory postures. It may be that in the pine stand, these behaviors were not effective in relieving the effects of prolonged exposure to direct sunlight. An additional light-related variable which was not measured in this study, yet which could serve as a proximate cue, is the difference in light intensity between the two habitats. However, Enders (1972) demonstrated that certain forestdwelling orb weavers showed no preference for any particular level of light. Similar experiments are needed to clarify whether M. gracilis uses light-levels as a cue in its macrohabitat selection process.

Events which occur with a constant probability over time intervals as short as one day follow a negative exponential distribution (Bailey 1964; Ross 1970). Such events may be stimuli such as disturbance due to climatic factors, or cues from vegetation structure (Janetos 1982). The distribution of residence times in the pine stand followed a negative exponential distribution. This is indirect support that vegetation structure and climatic factors influenced the frequent relocation in the pine stand. In contrast, the probability of moving increased with the number of days at a web site in the deciduous forest. In a subsequent study, I have found that this nonrandom distribution of residence times in the forest is related to hunger, a stimulus that has a cumulative rather than a constant probability over time (Hodge 1988).

Reichert \& Gillespie (1986) have identified three components of habitat selection by spiders: 1) the incentive to move; 2) movement curtailed upon encountering a favorable new environment; and 3) active search for a specific microhabitat. In $M$. gracilis, the incentive to move persists in the pine stand, as indicated by the short residence times. In the deciduous forest, spiders relocate much less 
frequently. This cessation of movement phase corresponds with the spider's entrance into a structurally and thermally favorable environment. Further studies of $M$. gracilis have shown that movement within the deciduous forest reflects the process of microhabitat selection, which only occurs after a suitable macrohabitat has been found (Hodge 1988).

\section{SUMMARY}

Release experiments were conducted to determine whether habitat selection is involved in producing the characteristic distribution of Micrathena gracilis, a forest-dwelling orb weaving spider. Marked spiders were released into a study area which included a deciduous forest habitat and an adjacent open pine habitat where spiders were previously never seen. Daily censusing and recording of movements revealed that spiders in the pine habitat spent significantly less time at web sites than did those released into the deciduous forest. Almost all of the spiders released into the pine stand, through successive web relocations, moved into the deciduous area, while none of the spiders released into the deciduous area was ever observed to enter the pine stand. Differences in prey availability, solar radiation and structural properties of the two habitats are suggested as factors involved in the observed macrohabitat choice.

\section{ACKNOWLEDGMENTS}

I would like to thank Drs. R. W. Matthews and J. O. Howell for providing me with the financial support and the opportunity to conduct this research. Dr. J. Arnold gave statistical advice, and Drs. A. Rypstra and G. W. Uetz offered valuable editorial assistance. I am especially grateful for the inspiration and support of Drs. J. Martyniuk, G. Morrison, G. W. Uetz, and R. S. Wilcox. This research was supported by the University of Georgia, Department of Entomology, Athens, Georgia, and the Georgia Experiment Station, Experiment, Georgia.

\section{REFERENCES}

BaILeY, N. T. J. 1964. The elements of stochastic processes with applications to the natural sciences. J. W. Wiley \& Sons, Inc. New York, N.Y.

BIERE, J. M. 1977. Web orientation in the spider Micrathena gracilis (Araneae: Araneidae). M.S. Thesis. University of Cincinnati. 
Biere, J. M. AND Uetz, G. W. 1981. Web orientation in the spider Micrathena gracilis (Araneae: Araneidae). Ecology 62: 336-344.

BrockmanN, H. J. 1979. Nest-site selection in the great golden digger wasp, Sphex ichneumoneus L. (Sphecidae). Ecol. Ent. 4: 211-224.

CARrel, J. E. 1978. Behavioral thermoregulation during winter in an orbweaving spider. Symp. Zool. Soc. Lond. 42: 41-50.

Castillo, J. A. and Eberhard, W. G. 1983. Use of artificial webs to determine prey available to orb weaving spiders. Ecology 64: 1655-1658.

Colebourn, P. H. 1974. The influence of habitat structure on the distribution of Araneus diadematus Clerck. J. Anim. Ecol. 43: 401-410.

Douglas, R. J. 1976. Spatial interactions and microhabitat selections of two locally sympatric voles, Microtus montanus and Microtus pennsylvanicus. Ecology 57: 346-352.

EberhaRD, W. G. 1971. The ecology of the web of Uloborus diversus (Araneae: Uloboridae). Oecologia 6: 328-342.

Elliot, F. R. 1930. An ecological study of the spiders of the beech-maple forest. Ohio J. Sci. 30: 1-22.

ENDERS, F. A. 1972. Web site selection by Argiope aurantia Lucas and other orb weaving spiders (Araneidae). Ph.D. Thesis. North Carolina State University, Raleigh, N.C.

ENDERs, F. A. 1976. Effects of prey capture, web destruction and habitat physiognomy on web site tenacity of Argiope spiders (Araneidae). J. Arachnol. 3: 75-82.

HARTSOCK, S. P. 1983. The influence of web structure and web placement on prey capture in orb-weaving spiders. M.S. Thesis. University of Cincinnati, Cincinnati, $\mathrm{OH}$.

HodGE, M. A. 1985. Macro- and microhabitat selection by the spiny orb weaving spider Micrathena gracilis (Walckenaer). M.S. Thesis. University of Georgia, Athens, GA.

HodGe, M. A. 1988. Factors influencing web site residence time of the orb weaving spider, Micrathena gracilis. Psyche, 94: 363-371.

Janetos, A. C. 1982. Foraging tactics of two guilds of web-spinning spiders. Behav. Ecol. Sociobiol. 10: 19-27.

KraKauer, T. 1972. Thermal responses of the orb-weaving spider Nephila clavipes (Araneae: Argiopidae). Am. Midl. Nat. 88: 246-250.

KREBS, C. J. 1985. Ecology: the experimental analysis of distribution and abundance. 3rd ed. Harper \& Row, New York.

Levi, H. W. 1985. The spiny orb-weaver genera Micrathena and Chaetacis (Araneae: Araneidae). Bull. Mus. Comp. Zool. 150: 429-618.

Levins, R. 1968. Evolution in changing environments: some theoretical explorations. Princeton Univ. Press, Princeton, N.J.

Lindauer, M. 1961. Communication among social bees. Harvard Univ. Press, Cambridge, MA.

Riechert, S. E. AND Gillespie, R. 1986. Habitat choice and utilization in the web-building spiders. In: Shear, W. A. (ed.), Spiders: webs, behavior, and evolution. Stanford University Press. 
Robinson, M. H. AND Robinson, B. 1974. Adaptive complexity: the thermoregulatory postures of the golden web spider Nephila clavipes, at low latitudes. Am. Midl. Nat. 92: 306-396.

Ross, S. M. 1970. Applied probability models with optimization applications. Holden-Day, San Francisco, Calif.

Tolbert, W. W. 1976. Thermal stress of the orb-weaving spider Argiope trifaciata (Araneae). Oikos 32: 386-392.

Uetz, G. W., Johnson, A. D. And Schemske, D. W. 1978. Web placement, web structure, and prey capture in orb-weaving spiders. Bull. Brit. Arachnol. Soc. 4: 141-148.

WeCKER, S. C. 1963. The role of early experience in habitat selection by the prairie deermouse, Peromyscus maniculatus bairdi. Ecol. Monogr. 33: 307-325.

Whitham, T. G. 1979. Habitat selection by Pemphigus aphids in response to resource limitation and competition. Ecology 59: 1164-1176. 

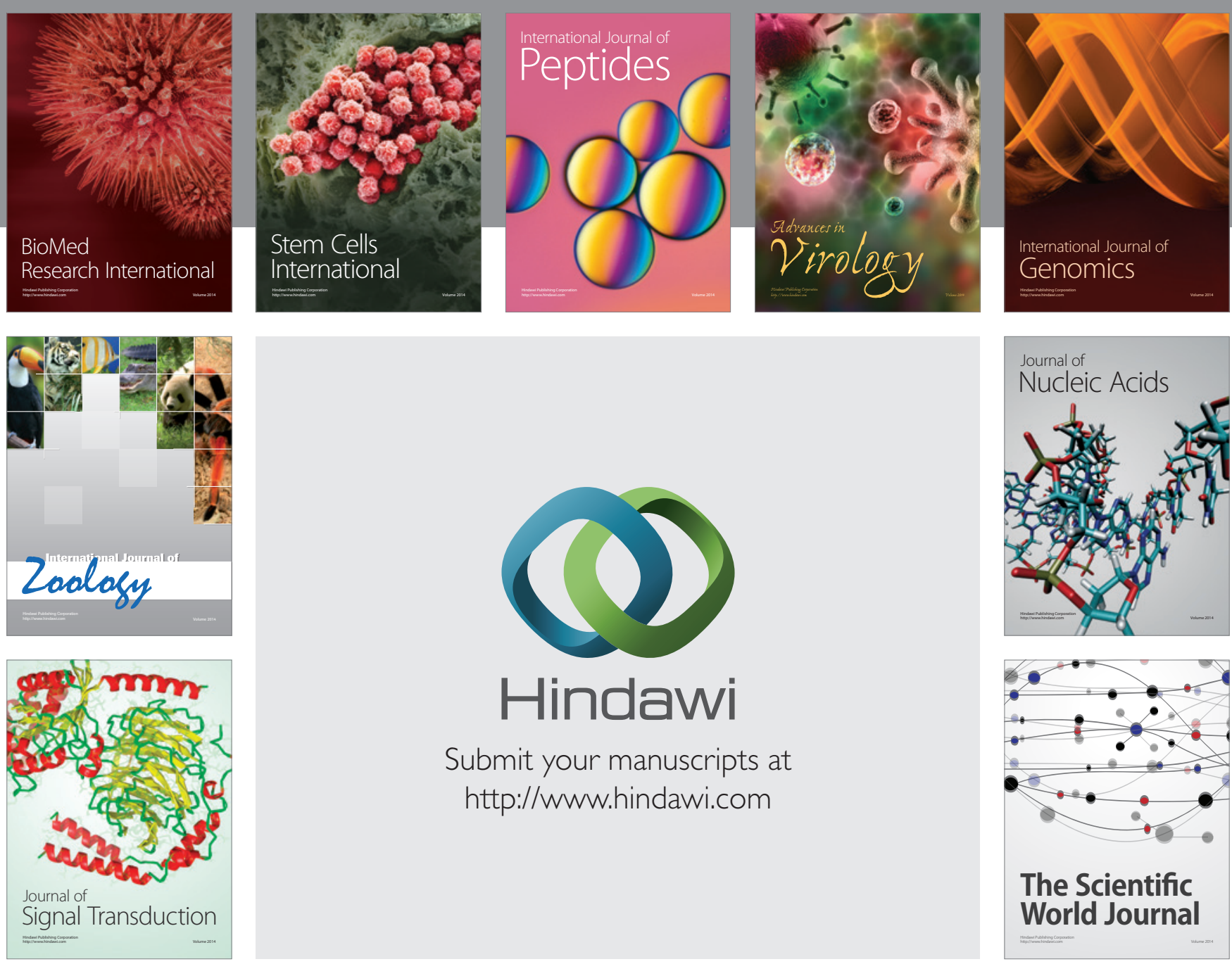

Submit your manuscripts at

http://www.hindawi.com
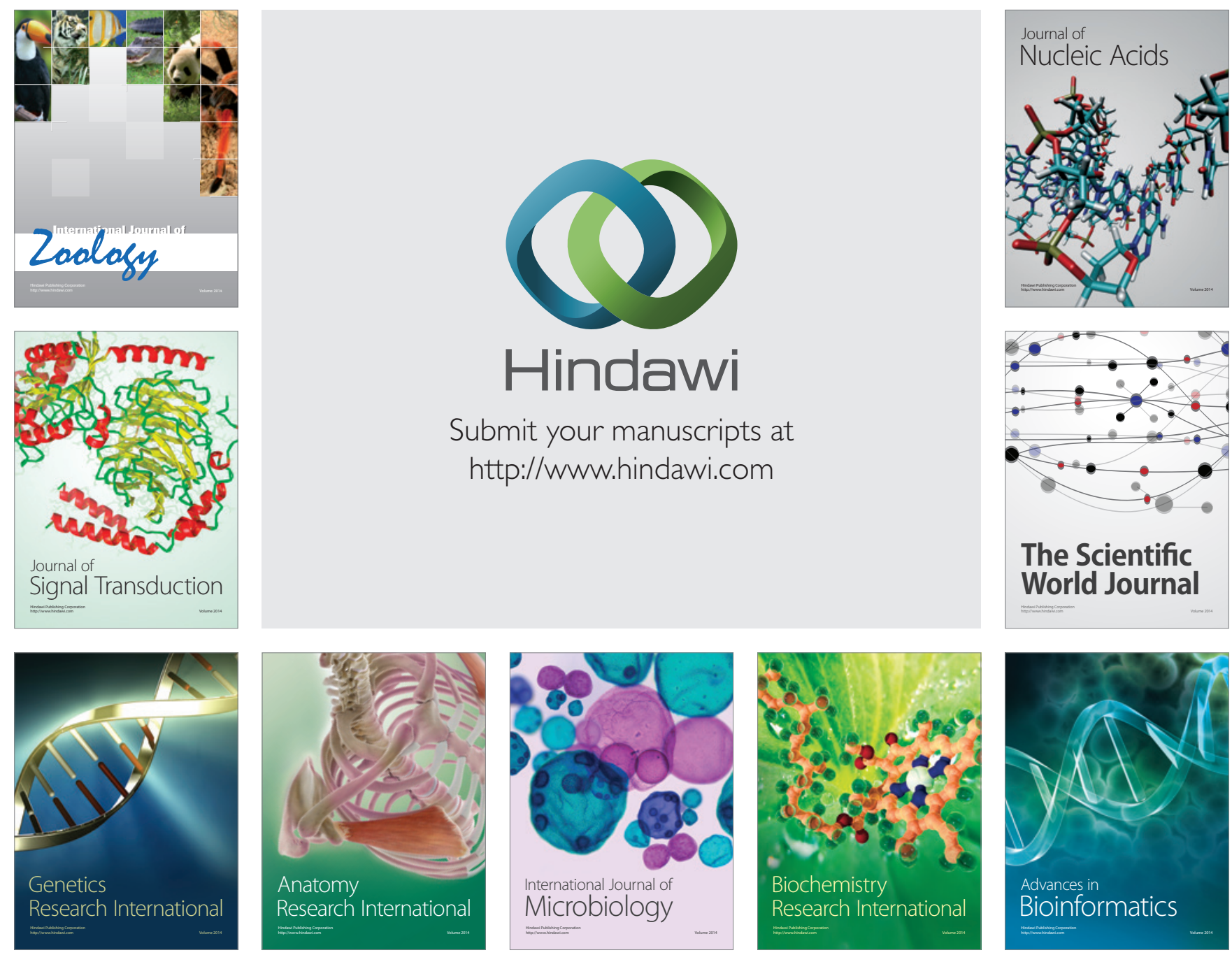

The Scientific World Journal
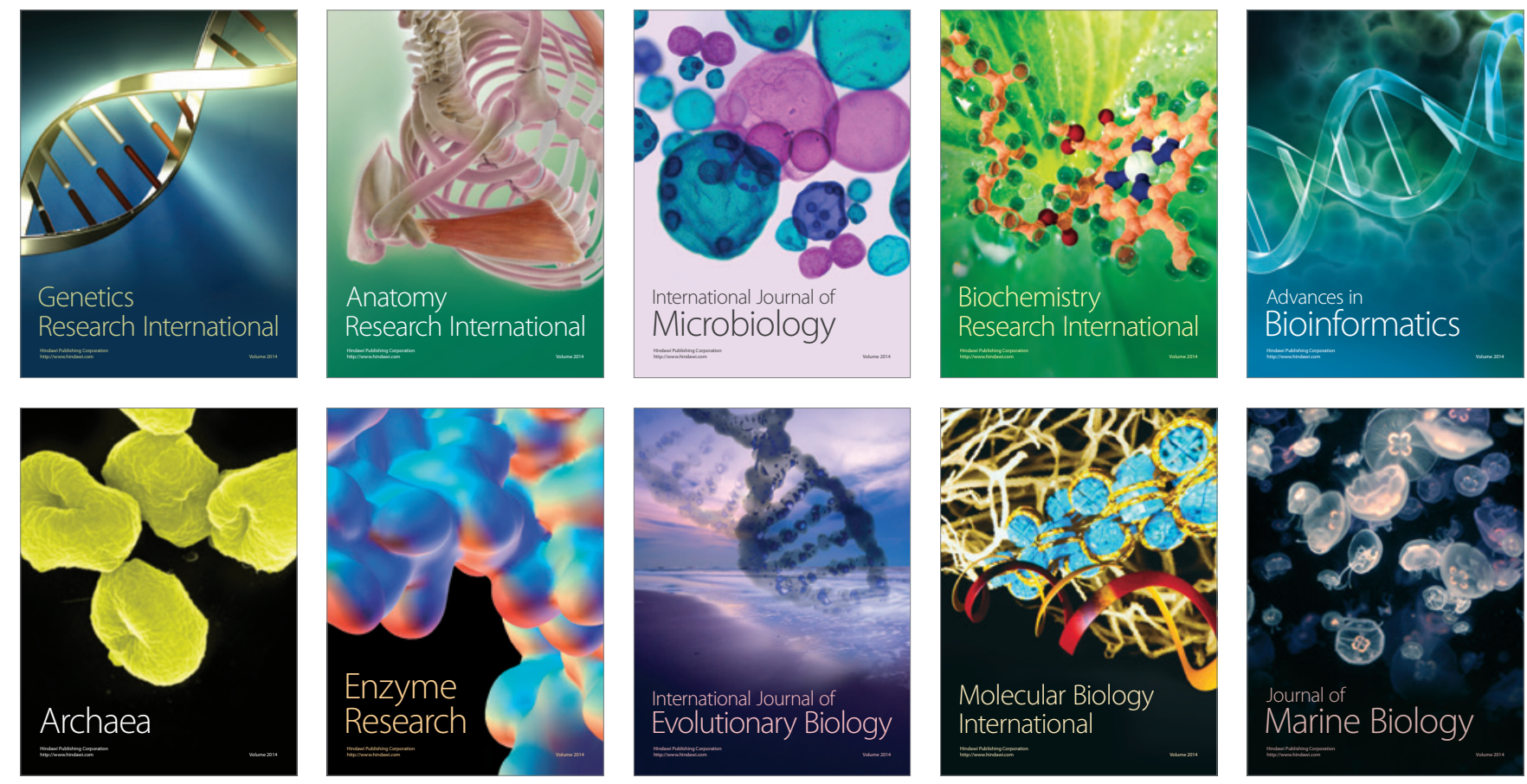